\title{
Evaluation of Anatomical Variations in Maxillary Sinus and Management of Chronic Sinonasal Disease
}

\author{
Ganesh Manohar Vihapure ${ }^{1}$, Akshay Sorade 2 , Kaenat Ahmed ${ }^{3}$, Lakshmi Sravya Yarlagadda ${ }^{4}$, Khaleel Basha Munnaru ${ }^{5}$ \\ 1,3,4,5 Department of Otorhinolaryngology, Krishna Institute of Medical Sciences Deemed To Be University, \\ Karad, Maharashtra, India, ${ }^{2}$ Department of ENT, Government Medical College, Jalgaon, Maharashtra, India.
}

\section{ABSTRACT}

\section{BACKGROUND}

The paranasal sinuses (PNS) have various anatomical difference. Computed tomography (CT) is an excellent means of providing anatomical information of this region, disease extent, assisting endoscopic evaluation and guiding treatment. Functional endoscopic sinus surgery (FESS) has become an increasingly popular treatment for chronic sinus diseases. CT of the paranasal sinuses has become a roadmap for FESS. The present study focuses on the assessment of the efficacy, safety and benefits of functional endoscopic sinus surgery in cases of maxillary pathologies and also study the anatomical variations in maxillary sinus in computed tomography and its usefulness in planning and management of chronic sinonasal diseases.

\section{METHODS}

It was a prospective study and a total of 80 patients were included in this study from July 2019 to June 2020 in the Otolaryngology Department, KIMS, Karad. Standard surgical steps were applied in each case according to the extent of disease. All patients underwent standard post-operative care. All findings were recorded and studied.

\section{RESULTS}

Total number of patients were 80 . Of which, 31 (38.75\%) patients were operated for ethmoidal polyp, 24 (30\%) for chronic rhinosinusitis, 10 (12.5\%) for antrochoanal polyp, 9 (11.25\%) for rhinosporidiosis and 6 (7.5\%) for inverted papilloma. Postoperative complications were periorbital echymoses (13\%), synechiae (2.5\%), epiphora (2.5\%), infection (2.5\%), hemorrhage ( $4 \%$ ). Complete relief of symptoms were noted in $81.67 \%$ cases.

\section{CONCLUSIONS}

Successful outcome and patient satisfaction post treatment can be obtained by careful evaluation and patient selection by history, examination and most importantly, proper imaging of the sinuses.

\section{KEY WORDS}

Maxillary Sinus, Sinusitis, Nasal Polyp, Paranasal Sinus Disease, Computed Tomography (CT)
Corresponding Author:

Dr. Akshay Sarode,

Department of ENT,

Government Medical College,

Jalgaon - 443402, Maharashtra, India.

E-mail: kaenatahmed3008@gmail.com

DOI: $10.14260 /$ jemds/2021/680

How to Cite This Article:

Vihapure GM, Sorade A, Ahmed K, et al. Evaluation of anatomical variations in maxillary sinus and management of chronic sinonasal disease. J Evolution Med Dent Sci 2021;10(38):3351-3355, DOI: 10.14260/jemds/2021/680

Submission 20-05-2021, Peer Review 30-07-2021, Acceptance 06-08-2021, Published 20-09-2021.

Copyright (C) 2021 Ganesh Manohar Vihapure et al. This is an open access article distributed under Creative Commons Attribution License [Attribution 4.0 International (CC BY 4.0)] 


\section{BACKGROUND}

In the intrauterine life, the skull bones develop in the first trimester. Mucosa in the nasal cavity invades the cranial cavity to form hollow cavitatory structure that would later form the paranasal sinuses. Due to this process of formation, there are various aberrations in the anatomical structure of the sinuses. Anatomical information of maxillary sinus and extent of disease is best evaluated by a radiological technique named computed tomography which is used to assist endoscopic evaluation and treatment. While magnetic resonance imaging (MRI) maybe useful in providing information regarding soft tissue inflammation and also fungal infections. ${ }^{1,2}$

The maxillary sinus in humans is inferiorly related to the upper alveolar surface and is hence easily prone to infections along with other causes of sinonasal inflammation. This cavity, therefore is very important in rhinology and oromaxillofacial surgery. The anatomical understanding of this area is of utmost importance before attempting to operate as it has varied attachments and associations with structures of that being delicate and imperative.

The structural area forms a collective route for drainage of the sinonasal secretions of maxillary, anterior ethmoidal and frontal sinuses. It is together called the osteomeatal complex (OMC). The OMC is the most important component in FESS. Variance in the anatomy of the OMC must be extensively studied in order to plan surgery.3,4

Opening of maxillary sinus in live patient is small and usually not easily seen because the opening is largely closed by the descending process of lacrimal bone anteriorly, the uncinate process of the ethmoid bone antero inferiorly, maxillary process of inferior turbinate inferiorly, perpendicular plate of palatine bone posteriorly. ${ }^{5}$ One of the anatomical variations that leads to development of chronic maxillary sinusitis is accesory maxillary osteum (AMO). However, it is not yet confirmed whether these ostea are acquired / congential. ${ }^{6}$ Most accepted theory for formation of accessory osteum is either by obstruction of main osteum due to sinusitis or due to diseases of middle meatus rupturing the membranous areas of fontanelle. ${ }^{7}$ The fontanelle are regions in the middle meatus located above the inferior turbinate and below the uncinate process and covered by mucosa of maxillary sinus laterally with connective tissue sandwiched between the two. Depending on the location with respect to uncinate process, they are anterior nasal fontanella (ANF) and posterior nasal fontanella (PNF). ${ }^{8}$ Maxillary sinus ostium does not open directly into nasal cavity owing to it being located on the highest part of medial wall of sinus. Maxillary sinus ostium opens into narrow ethmoidal infundibulum, the inflammation of which can further lead to disturbance in drainage. ${ }^{9}$ Location of accessory maxillary ostium is $5-10 \mathrm{~mm}$ superior to the attachment of inferior concha and opens to the lateral nasal wall. Due to the presence of accessory maxillary ostia, a two fold increase in incidences of maxillary sinusitis is observed. During endoscopic sinus surgeries, it is imperative to differentiate primary maxillary ostium from accessory maxillary ostium so as to achieve optimum results and avoid orbital injuries. Another point to be noted is that ethmoid infundibulum is actually a three-dimensional structure and not two-dimensional as visible in CT. It is not possible to visualize the ostium endoscopically without removing the uncinate process as the maxillary sinus ostium opens into the floor of ethmoid infundibulum. Visibility of ostium endoscopically most likely represents accessory ostium or fontanelle. The hiatus semilunaris is named so due to the arched appearance in sagittal plane, situated posteroinferiorally between uncinate process and bulla ethmoidalis, best identified on parasagittal sections. Boundaries on CT are superiorally bulla ethmoidalis, laterally medial bony wall of orbit, inferiorally uncinate process and middle meatus medially. Final drainage pathway from maxillary sinus and ethmoidal infundibulum is hiatus semilunaris which connects medially with the middle meatus. View of uncinate process varies through an endoscope (threedimensional) and through CT scans (two-dimensions). Its attachments anteriorly are nasolacrimal apparatus, inferiorly turbinate, posteriorly it has a free margin and superiorly variable. Whereas on CT, attachments can be seen as inferiorly turbinate with the free edge depicting the posterior free margin.

Anteriorly, it may be attached to lamina papyracea, middle turbinate or the skull base. These variable attachments results in different clinical outcomes. The ethmoid infundibulum would be effectively closed superiorly by a blind ending pouch known as recessus terminals if the uncinate process inserts into the lamina papyracea. The explanation for why ethmoid infundibular inflammation does not result in concomitant frontal sinusitis can be given by separation of the frontal recess and ethmoid infundibulum. In order for frontal sinus to open into the ethmoid infundibulum, uncinate process has to be attached superiorly to the skull base or the middle turbinate. This arrangement may cause recurrent infections in infundibulum impacting the frontal sinus leading to involvement of all three frontal, ethmoid and maxillary sinuses.

Millions of individuals are affected by chronic rhinosinusitis (CRS) characterized by inflammation of paranasal sinuses and nose. It is also one of the most common disorders of upper airway. CRS can be classified as:

\begin{tabular}{|cc|}
\hline Acute & Lasting 4 weeks \\
Sub-acute & 4 to 12 weeks \\
Chronic & More than 12 weeks \\
\hline \multicolumn{2}{|c|}{} \\
\hline
\end{tabular}

It is also associated with other nasal pathologies such as nasal polyposis. Evidence is available to indicate that $80 \%$ polyp arises from middle meatal mucosa, infundibulum, uncinate process. ${ }^{10,11}$ Etiology includes multiple factors such as allergy, infection, chemical, trauma, metabolic disease and psychogenic factors. ${ }^{12}$ Most popular line of treatment for CRS is functional endoscopic sinus surgery. Advancements in technology has happened with development of small fibre optic endoscopes and computerized tomography which provides us with more direct and accurate study of sinonasal diseases which was previously impossible. CT acts as a roadmap for FESS. Regional anatomical variations are better understood by CT and it has been an important tool guiding the surgical procedures.

The scope for sinus surgeries has increased due to betterment of FESS and CT technology. The objective of this study was to study the anatomical variations in maxillary sinus in computed tomography and its usefulness in planning and management of chronic sinonasal diseases. 
This study aims at assessment of efficacy, safety and benefits of functional endoscopic sinus surgery in cases of CRS, allergic and non-allergic nasal polyposis and the application of studying the anatomy of the sinuses and their variances beforehand in order to reduce morbity and recurrence along with improving patient outcomes.

\section{METHODS}

It was a prospective type of study with a total of 80 (eighty) patients being studied from July 2019 to June 2020 in the Department of ENT, KIMS, Karad. All patients who were more than 15 years of age and less than 45 years with sinonasal complaints were included in this study. Patients with neoplastic diseases and history of trauma of nose or face were excluded from the study. All patients with previous surgery were also excluded from this study. An ethical approval was granted by the university ethical committee via letter number KIMSDU / IEC / 17 / 2019.

\section{Planning}

The X-ray of the paranasal sinuses: Water's view and occasionally lateral view including nasopharynx were done when clinically polyps extended in the nasopharynx, for initial screening. CT PNS (coronal and axial) provided the surgeon with a roadmap and acted as the guide to the surgeon in planning the operative procedure and in assessing the prognosis and success of surgery.

\section{Procedure}

We performed FESS under general anaesthesia in each case after obtaining informed consent. Standard surgical steps were applied in each case according to the extent of disease. For this study, we used rigid endoscopes with deflection angles of 0 and 30 degrees. The endoscope was $18 \mathrm{~cm}$ long with glass rod lenses (Hopkins system) with an outer diameter of $4 \mathrm{~mm}$. Endoscopic pictures were taken. No premedication was required.

All patients were prescribed with nasal steroid drops, oral antihistamines and antibiotics post-operatively. Some patients were given oral antifungal medicines too. Every patient was assessed by nasoendoscopy post-operatively and regular nasal toilet and debridement of nasal adhesions and crusting was done on each follow-up visit. Findings intra operatively and on HPR of the tissue obtained during surgery was compared with the CT scan findings of the patients in order to draw conclusions.

\section{Statistical Analysis}

Chi square test was used to compare the outcome. All data analysis was done using Statistical Package for Social Sciences (SPSS) version 2.0. This study ruled out all patients with previous history of surgery or trauma to nose. Thus the implication of anatomical variations caused by iatrogenic or external causes and its effect on pathogenesis could not be assessed.

\section{RESULTS}

Total number of patients were 80. Of which, 31 (38.75\%) patients were operated for ethmoidal polyp, 24 (30\%) for chronic rhinosinusitis, 10 (12.5\%) for antrochoanal polyp, 9 $(11.25 \%)$ for rhinosporidiosis and 6 (7.5\%) for inverted papilloma. Intra operative difficulties were gross deviated nasal septum (DNS) 10(12.5\%), unusual bleeding 8 (10\%), concha bullosa 6 (7.5\%), obstructed osteomeatal complex (OMC) in 7 cases. Agger nasi cells were seen in 6 cases and accessory maxillary osteum in 10 cases.

Out of the above, it was noted that, gross DNS was seen on CT in 10 cases and choncha bullosa was seen in 7 cases. The obstruction in OMC was seen in 5 cases, agger nasi cells were seen in 6 cases and accessory maxillary osteum in 8 cases. The number of patients that presented with intra operative complications were 63 .

The number of patients with intra operative complications predicted by CT findings were 56 . Statistically this is not significant by chi square calculator for goodness of fit, with the chi square value 2.917 and the $\mathrm{P}$ value $0.08767(\mathrm{P}<0.01$ is significant).

Although the scan accurately predicted the patients of gross DNS and agger nasi cells and almost perfectly diagnosed cases with choncha bullosa and OMC obstruction, there isnt a modality that would predict the number of cases that would have an unusual amount of intra operative bleeding. This is the cause of an unusual skewness in the predictive value of scans for complications. Ethmoidal polyposis was diagnosed in 30 cases, chronic sinusitis in 26, antrochoanal polyp and rhinosporidiosis in 7 each and 10 were diagnosed with schniederian papilloma.

This was significantly related to the intra operative finding in the patients with $\mathrm{P}$ value 0.16168 (chi square value: 3.6442). Post-operative complications were periorbital echymoses (13\%), Synechiae (2.5\%), Epiphora (2.24\%), infection (2.67\%), hemorrhage (4.33\%). Complete relief of symptoms were noted in $81.67 \%$ cases.

Majority of patients $62(77.5 \%)$ were released from the hospital on 2nd post-operative day. Out of 80 patients, the most common anatomical variation associated were septal deviation $62.5 \%$, concha bullosa is pneumatization of middle turbinate $47.5 \%$ cases, paradoxically middle turbinate $28.7 \%$ cases. Agger nasi cells $21.25 \%$ and haller cells in $13.7 \%$ cases on CT.

No major pre-operative complication occurred in this, however, 2 patients presented post-operative ecchymosis, one patient presented diplopia and blurring in vision, one patient presented with headache, one with orbital sub-cutaeneous emphysema, and 2 patients were with post-operative synechia formation.

\begin{tabular}{|ccc|}
\hline & $\begin{array}{c}\text { Intra Operative and } \\
\text { HPR Findings }\end{array}$ & Findings on CT PNS \\
Operated for ethmoidal & $31(38.75 \%)$ & 30 \\
polyp & $24(30 \%)$ & 26 \\
$\begin{array}{c}\text { Chronic rhinosinusitis } \\
\text { Operate for antrochoanal } \\
\text { polyp }\end{array}$ & $10(12.5 \%)$ & 7 \\
$\begin{array}{c}\text { Operated for } \\
\text { rhinosporidiosis }\end{array}$ & $9(11.25 \%)$ & 7 \\
$\begin{array}{c}\text { Operate for inverted } \\
\text { papilloma }\end{array}$ & $6(7.5 \%)$ & 10 \\
\hline Table 1. Outcomes In Cases Of Maxillary Sinusitis (N=60) \\
\hline
\end{tabular}




\begin{tabular}{|ccccc|}
\hline & $\begin{array}{c}\text { Intra Operative } \\
\text { Findings }\end{array}$ & $\begin{array}{c}\text { Findings } \\
\text { Predicted on } \\
\text { CT PNS }\end{array}$ & $\begin{array}{c}\text { Chi Square } \\
\text { Value }\end{array}$ & P Value \\
Without any & $56(70 \%)$ & 63 & 2.917 & 0.08 \\
complications & $10(12.5 \%)$ & 10 & 90 & $<0.0001$ \\
Gross D.N.S & $08(10 \%)$ & $\mathrm{NA}$ & $\mathrm{NA}$ & NA \\
Unusual bleeding & $06(7.5 \%)$ & 7 & 112.24 & $<0.0001$ \\
Concha bullosa & 06 & 115.672 & $<0.0001$ \\
Obstructed OMC & $7(8.75 \%)$ & 6 & 90 & $<0.0001$ \\
Agger nasi cells & $6(7.5 \%)$ & 10 & 96.1601 & $<0.0001$ \\
\hline Accessory ostium & $8(10 \%)$ & Table 2. Intra Operative Complications \\
\hline \multicolumn{5}{r}{} \\
\hline \multicolumn{5}{r}{} \\
\hline
\end{tabular}

\begin{tabular}{|cc|}
\hline No Post-Operative Complications & $\mathbf{6 0}(\mathbf{7 5} \%)$ \\
Synechiae & $02(2.5 \%)$ \\
Epiphora & $02(2.5 \%)$ \\
Infection & $02(2.5 \%)$ \\
Haemorrhage & $03(4.33 \%)$ \\
Periorbital edema & $11(13 \%)$ \\
\hline Table 3. Post-Operative Complications \\
\hline
\end{tabular}

\begin{tabular}{|cc|}
\hline Complete Relief & $\mathbf{8 1 . 6 7 \%}$ \\
Partial relief & $11.67 \%$ \\
Persistent disease & $6.67 \%$ \\
\hline Table 4. Outcome In Cases Operate For Maxillary Sinusinitis. \\
\hline
\end{tabular}

\begin{tabular}{|cc|}
\hline $\begin{array}{c}\text { Discharged on Post-op Day } 2 \\
\text { Discharged on post-op day } 7\end{array}$ & $\mathbf{6 2}(77.5 \%)$ \\
\hline Table 5. Stay In Hospital \\
\hline
\end{tabular}

\section{DISCUSSION}

The otorhinolaryngologist must have a detailed knowledge of anatomical variations of maxillary sinus opening in any interventional maxillary sinus surgeries as it relates to the orbital floor, ethmoid infundibulum and nasolacrimal duct. In adults, the maxillary sinus can be described as triangular in shape, measuring $25 \mathrm{~mm}$ along the anterior limb of its base, 34 $\mathrm{mm}$ in depth and $33 \mathrm{~mm}$ in height.12,13 The sinus can be partially compartmentalized by either complete or incomplete septa. Knowledge of the incidence and morphology of maxillary sinus septa has clinical implications especially in FESS. It is indicative of the amount of dissection required for complete clearance of the sinus. Total 80 (eighty) patients were included in this study who were fulfilling certain inclusion and exclusion criteria, were studied prospectively at KIMS, Karad from July 2019 to June 2020. Several disease entities were treated endoscopically in this study which is consistent with other standard studies. All patients underwent CT-PNS pre-operatively in order to study the anatomy of the nasal cavity and sinonasal sinuses. FESS was performed on all patients after a written informed consent and the findings were noted and compared. All samples collected were sent for histopathology and the findings were studied along with CT findings. In this study it was found that $38.75 \%$ patients were operated for ethmoidal polyp, $30 \%$ patients for chronic rhinosinusitis, $12.5 \%$ for antrochoanal polyp, $11.25 \%$ patients for rhinosporidiosis, $7.5 \%$ for inverted papilloma. In this series of FESS, most of the patients 65 (81.67\%) were operated without facing any difficulties. But, some difficulties like, gross DNS 10 (12.5\%), unusual bleeding 8 (10\%) and concha bullosa $6(7.5 \%)$ were faced and managed accordingly. Phatak et al. ${ }^{14}$ in a study in 2019 had similar findings $12 \%$ patients having agger nasi cells and $6 \%$ patients having accessory maxillary osteum. In a study by Bajoliya et al. ${ }^{15}$ the number of patients with agger nasi cells were $6.5 \%$. This is similar to our study where $7.5 \%$ of the patiens presented with agger nasi cells. No post-operative complications of FESS were found in 66 (81.67\%) patients; periorbital ecchymoses 9 (13\%), hemorrhage 3 (4.33\%), synechiae 2 (2.5\%), epiphora $2(2.5 \%)$ and infection $2(2.5 \%)$ were found during postoperative follow up. Although these findings were consistent with the study of Rahman MJ et al. ${ }^{16}$ they were fairly inconsistent with the study of Gross et al. ${ }^{17}$ where $1 \%$ synechiae was found. This study was consistent with the findings in a study by Jin et al. ${ }^{18}$ Overall, $81.67 \%$ had complete relief of symptoms after FESS, $11.67 \%$ patients experienced partial relief and $6.67 \%$ of patients observed persistence of diseases. In this respect, this study is fairly similar with the study of Smith LF et al. Majority of patients 46 (76.67\%) were discharged from the hospital after 02 days of FESS and 13 $(23.33 \%)$ were discharged after 07 days for management of various complications.

\section{CONCLUSIONS}

Endoscopic sinus surgery has brought a revolution in the treatment of sinonasal pathologies and has made the anatomically elusive distant sinuses accessible. The paranasal sinuses have important relations such as the orbit, cranial nerves, anterior ethmoidal artery or the NLD along with significant anatomical variances thus making imaging imperative in order to plan the surgical management of the patient and provide satisfactory relief to the patient. Successful outcome of operation can be obtained by careful evaluation and patient selection by history, examination and proper imaging of the sinuses. Accurate evaluation in the form of imaging is mandatory to acquire proficiency in functional endoscopic sinus surgery. There are significant anatomical variances in paranasal sinuses thus making imaging imperative in order to plan the surgical management of the patient and provide satisfactory relief to the patient.

Data sharing statement provided by the authors is available with the full text of this article at jemds.com.

Financial or other competing interests: None.

Disclosure forms provided by the authors are available with the full text of this article at jemds.com.

\section{REFERENCES}

[1] Chong VF, Fan YF. Comparison of CT and MRI features of sinusitis. Eur J Radiol 1998;29(1):47-54.

[2] Basílio FMA, Arantes MC, Ballin AC, et al. Efficacy of endoscopic sinus surgery in the treatment of chronic rhinosinusitis. Intl Arch Otorhinolaryngol São PauloBrazil 2010;14(4):433-7.

[3] Singhal MD, Singhal D. Maxillary sinus ostiummorphology and its clinical relevance. CIBTech J Surg 2013;2(3):26-9.

[4] Sindel A, Turhan M, Ogut E, et al. An endoscopic cadaveric study: accessory maxillary ostia. Dicle Med J 2014;41(2):262-7.

[5] Lang J, Sakals E. Über die Höhe der Cavitasnasi, die Längeihres Bodens und Ma ßesowie Anordnung der Conchae nasales. Anat Anz 1981;149:297-318. 
[6] Genc S, Ozcan M, Titiz A, et al. Development of maxillary accessory ostium following sinusitis in rabbits. Rhinology 2008;46(2):121-4.

[7] Levine HL, Mark M, Rontal M, et al. Complex anatomy of lateral nasal wall simplified for endoscopic sinus surgery. New York: Thieme Medical Publishers 1993: p. 1-28.

[8] Zuckerkand lE. Die Siebbeinmuscheln des Menschen. Anat Anz 1892;7:13-25.

[9] Matthews BL, Burke AJ. Recirculation of mucus via accessory ostia causing chronic maxillary sinus disease. Otolaryngol Head Neck Surg 1997;117(4):422-3.

[10] Dale RH, Steven D. Schaefer endoscopic paranasal sinus surgery. $2^{\text {nd }}$ edn. New York: Lipinncott 1995.

[11] Bhattacharyya N. Influence of polyps on outcomes after endoscopic sinus surgery. Laryngoscope 2007;117(10):1834-8.

[12] Deshmukh KA, Deshmukh PK, Singi Y, et al. Role of endoscopic surgery in management of nasal polyps. Al Ameen J Med Sci 2013;6(4):364-8.
[13] Schaeffer JP. The nose, paranasal sinuses, nasolacrimal passageways and olfactory organ in man. Philadelphia: P. Blakiston's Son \& Co., 1920.

[14] Phatak S, Aggarwal R. Rhinosinusitis: How common are the anatomical variations responsible? Intech Open 2019.

[15] Bajoliya S, Maru YK, Goswami R. Evaluation of role of functional endoscopic sinus surgery in patients of sinonasal diseases \& nasal polyposis. Int J Med Res Rev 2015;3(2):190-6.

[16] Rahman MZ, Shaheen MM, Saha KL. FESS - a review of personal series of 207 Cases. J Dhaka Med Coll 2003;12(1):56-9.

[17] Gross RD, Shridan MF, Burgess LP. Endoscopic sinus surgery complications in residency. Laryngoscope 1997;107(8):1080-5.

[18] Jin G, Shi X, Gao H. Experience of endoscopic sinus operation on 74 cases. Lin Chuange Er Bi Yan Hou Ke Za Zhi 1999;13(8):354-5. 